\title{
The influence of income on medical school admissions in Canada: a retrospective cohort study
}

Tyler Pitre* ${ }^{*}$, Alexander Thomas, Kyle Evans, Aaron Jones, Margo Mountjoy and Andrew P. Costa

\begin{abstract}
Background: The socioeconomic status of applicants to Canadian medical schools has been understudied in the past two decades. Institutional efforts have been made to address the lack of socioeconomic diversity across Canada during this time. We investigated the income characteristics of medical school applicants, as well as the relationship between applicant income and offer of admission, to characterize the current state of socioeconomic diversity in medical admissions.
\end{abstract}

Methods: We conducted a retrospective cohort study on 26,120 applicants at one Ontario medical school from 2013 to 2018. Characteristics of applicants who were offered admission were compared to the general population and applicants not offered admission. Regression analyses were used to investigate the association between median total neighborhood income and successful admission.

Results: The median total neighborhood income for medical school applicants was $\$ 98,816$, which was approximately $\$ 28,480$ higher than the Canadian general population. Those not admitted to the medical school had a median total neighborhood income of $\$ 98,304$ compared to $\$ 105,984$ for those offered admission $(p<0.001)$. This trend was seen in every province and territory in Canada. Median total neighborhood income was a predictor of an offer of admission; applicants in the $>75$ th percentile income group had $54 \%$ increased odds of being offered admission when compared to applicants in the <25th percentile in our unadjusted model. Income was not significant in our adjusted models but showed that the income medians drastically shifted between pre-interview and post-interview periods, from $\$ 98,816$ to $\$ 104,960$ ( $p<0.001)$.

Conclusion: Medical school applicants are from higher economic strata compared to the general population. Despite already representing a high economic stratum, a higher median total neighborhood income relative to other applicants was associated with an offer of admission.

Keywords: Admissions, Socioeconomic status, Income, Medical admissions, Undergraduate medicine, MCAT, GPA, MMI, CASPer

* Correspondence: tyler.pitre@medportal.ca

Michael G. DeGroote School of Medicine Waterloo Regional Campus,

McMaster University, 10 Victoria Street South, Kitchener N2G 1C5, Canada 


\section{Background}

Selecting applicants for admission to medical school is a critical responsibility in medical education. The admissions process to Canadian medical schools is exceedingly competitive. Since most medical students graduate to practice in Canada, Faculties of Medicine must address the ability of future physicians to serve the diverse needs of individuals and communities first through their admissions process.

Concerns have been raised about the dearth of economic diversity among Canadian medical school students and the systemic barriers faced by potential applicants of lower socioeconomic status, such as the high application costs and lack of access to mentors [1]. Decades old research by Dhalla et al. (2002) demonstrated that Canadian medical students had higher average family income, parents with greater formal educational achievements, and were disproportionately from urban areas compared to the general population $[2,3]$.

In 2010, the Association of Faculties of Medicine of Canada (AFMC) had encouraged Canadian medical schools to support and select a representative mix of medical student candidates, in order to uphold their social mandate and to graduate a physician workforce better able to care and advocate for a diverse population [4]. Diversity in medicine is an important area of study, including wide ranging topics such as cultural competence, linguistic and racial diversity. For example, patient trust is improved by interaction of patients with doctors of similar ethnicity and background [5]. Furthermore, there is evidence that cultural competence training for health care workers leads to better patient outcomes [6]. For our purposes, we address socioeconomic diversity, defined as having students from different income levels and social backgrounds. In our models, we used median neighborhood income as a measure of applicant income, which does not capture individual income but is meant to be a surrogate measure of socioeconomic status.

The AFMC hypothesized that having physicians from a diverse socioeconomic background would be better able to understand unique health challenges and therefore help improve patient care [1]. Yet the socioeconomic status of Canadian medical students has been understudied in Canada, and - to our knowledge - the socioeconomic status of the applicant pool and its effect on receiving an offer of admission has not been studied. Importantly, there has been no studies to update whether there has been improvement in the socioeconomic makeup of medical school classes since the AFMC's call to action.

Our objective was therefore to describe the socioeconomic status of medical school applicants, those offered admission and whether income is an independent predictor of success using neighborhood income as a proxy measure for socioeconomic status. In addition, we aimed to identify what components of an applicant's application was associated with an offer of admission.

\section{Methods \\ Study design and data sources}

We conducted a retrospective cohort study of applicants to McMaster University's Michael G. DeGroote School of Medicine from 2013 to 2018. McMaster's Undergraduate Medical Program (initiated in 1969) is a threeyear program that admits approximately 200 students each year. In 2016/17, 74.6\% (4974/6672) of all applicants to an Ontario medical school applied to McMaster and $21.4 \%(206 / 964)$ of all admitted/registered medical students in Ontario medical school were for McMaster [7].

We obtained applicants' admission data for application years spanning 2013 to 2018 inclusive, from two separate files, from two different sources. The first source is from the Ontario Medical School Application Service (OMSAS). All Ontario medical schools use this service for applicants to apply, which provides each applicant a unique identification number. The OMSAS data file contained a parental postal code and Ontario medical school application number. The McMaster data file included OMSAS application numbers, application year, and whether applicants were offered admission (vs. not offered/waitlisted) and, if offered, whether the offer was accepted, declined, or deferred. Data files were combined using common Ontario medical school application numbers. We excluded repeat applicants, assuming that applicants would have used the same Ontario medical school applicant number for subsequent applications. We classified any offer of admission as such, regardless if the offer was accepted, declined, or deferred. Also available in the McMaster file were the applicants' demographic data, including age category, residency status (Ontario versus out-of-province), identified sex, and the postal code of their home address during high school. Admission testing criteria data included applicants' undergraduate university Grade Point Average (GPA), Medical College Admissions Test (MCAT) Critical Analysis and Reasoning (CARS; formerly Verbal Reasoning) score, Multi-Mini Interview (MMI) mean score, and CASPer scores. MCAT scores range from 118 to 132 with a median score of all test takers of approximately 125 for each section. As McMaster University only uses the CARS score, we only had access to this data point. CASPer z-scores are utilized as these are typically cited in the literature rather than absolute scores $[8,9]$. GPA is a standardized score out of 4.0, reflecting undergraduate academic success. McMaster uses a twopart formula to determine who receives an offer of admission. The first part of the formula is a pre-interview 
score, which is a composite of $33 \%$ for each of the MCAT, GPA and CASPer scores. The second part of the formula is a post-interview score, which is a composite of $70 \%$ for MMI and 15\% for GPA and MCAT respectively. Lastly, McMaster also preferentially interviews $80-90 \%$ of its applicants from Ontario, making geography an important variable to correct for in our model.

We incorporated a proxy measure of applicants' neighborhood income by including the 2015 median total household income for each applicants' home postal code during high school. Specifically, using the publicly available Postal Code Conversion File (PCCF), we matched each applicants' postal code to the most appropriate dissemination area (DA, a relatively stable geographic unit comprised of 400-700 individuals) from the 2016 Canadian Census in order to capture the 2015 median total neighborhood income. This method is a well-established mechanism of estimating neighborhood income [2, 1012]. However, using a DA as a comparative measure of median total household income for individual applicants may drastically underestimate or overestimate individuals within the DA. Therefore, the results need to be viewed within this context. An applicant's postal code of their home address during high school was considered ideal given that it defines the family household neighborhood area during a critical scholastic and developmental life stage.

\section{Statistical analysis}

Applicants' demographic data and admission testing scores were compared between those who were and were not offered admission. In addition, a sensitivity analysis was completed to rule out potential confounders by running the analysis without Ontario applicants included. This was done to protect from concentrated applicants in neighborhoods in the Greater Toronto Area with disproportionately higher neighborhood incomes, as too ensure generalizability. Binary logistic regression was used to characterize the relationship between an offer of admission and applicants' median neighborhood income. The neighborhood income variable was transformed into different variables representing quartiles of neighborhood income for comparison. Age, sex, application year, and residency (Ontario vs out-of-province) were included in the analysis to control for potential confounding and modifying effects that could also influence an offer of admission.

A second binary logistic regression was performed, first correcting for GPA, MCAT, CASPer and then MMI, GPA and MCAT, to investigate whether the results remained significant. These were modelled to reflect McMaster's pre and post interview formulas. The first model included all individuals applying, whereas the second model included only those applicants who had an MMI score, which compromised 2973 applicants total. These models only include year's 2016 to 2018 inclusive as only the newer MCAT CARS scores were used, although sensitivity analysis using the older verbal reasoning (VR) scores yielded similar results. However, because McMaster's formula for pre and post interview scores are determined solely by these factors, we hypothesize neighborhood income would play little to no role, as there would be no discretion for neighborhood income in this model.

Analysis was done to rule out multicollinearity between variables used. We also performed bivariate Pearson coefficient analysis on multiple admissions scores, offer of interview and neighborhood income to determine which elements were most highly associated with an offer of admission. All data analysis was completed using the Statistical Package for the Social Sciences (SPSS) software, version 24 for Mac (IBM, Armonk, $\mathrm{NY})$.

\section{Ethics approval}

Given the use of secondary de-identified data, strict information security, and institutional sponsorship/oversight, this project was granted a waiver of full review by the Hamilton Integrated Research Ethics Board based on low risk / quality improvement. Administrative review and release were granted by the admissions committee and assistant dean of medicine.

\section{Results}

We received data on 29,509 applications. Two separate data files were received, one from McMaster and the other from OMSAS. These files were merged using Ontario medical school application numbers, which was the common variable between the data sets. One hundred and ninety-six applicants were dropped during the merge because there were no matches between data sets, and an additional 3193 applications were dropped because a postal code was not recorded for these applications or repeat applications were identified, and therefore could not be included in the analysis. We were left with 26,120 applications where we could determine a median neighborhood income. Figure 1 is a flow chart representing the process outlined above.

\section{Demographics of socioeconomic diversity}

The mean age at the time of application was 23 years old. The female to male ratio was 14,397 (55.1\%) to 11 , 793 (44.9\%). In addition, 19,628 (75.0\%) of the applicants came from Ontario, whereas 15\% came from outside of Ontario, representing every province and territory. The total median neighborhood income of those applying was $\$ 98,816$. Applicants who were offered admission 


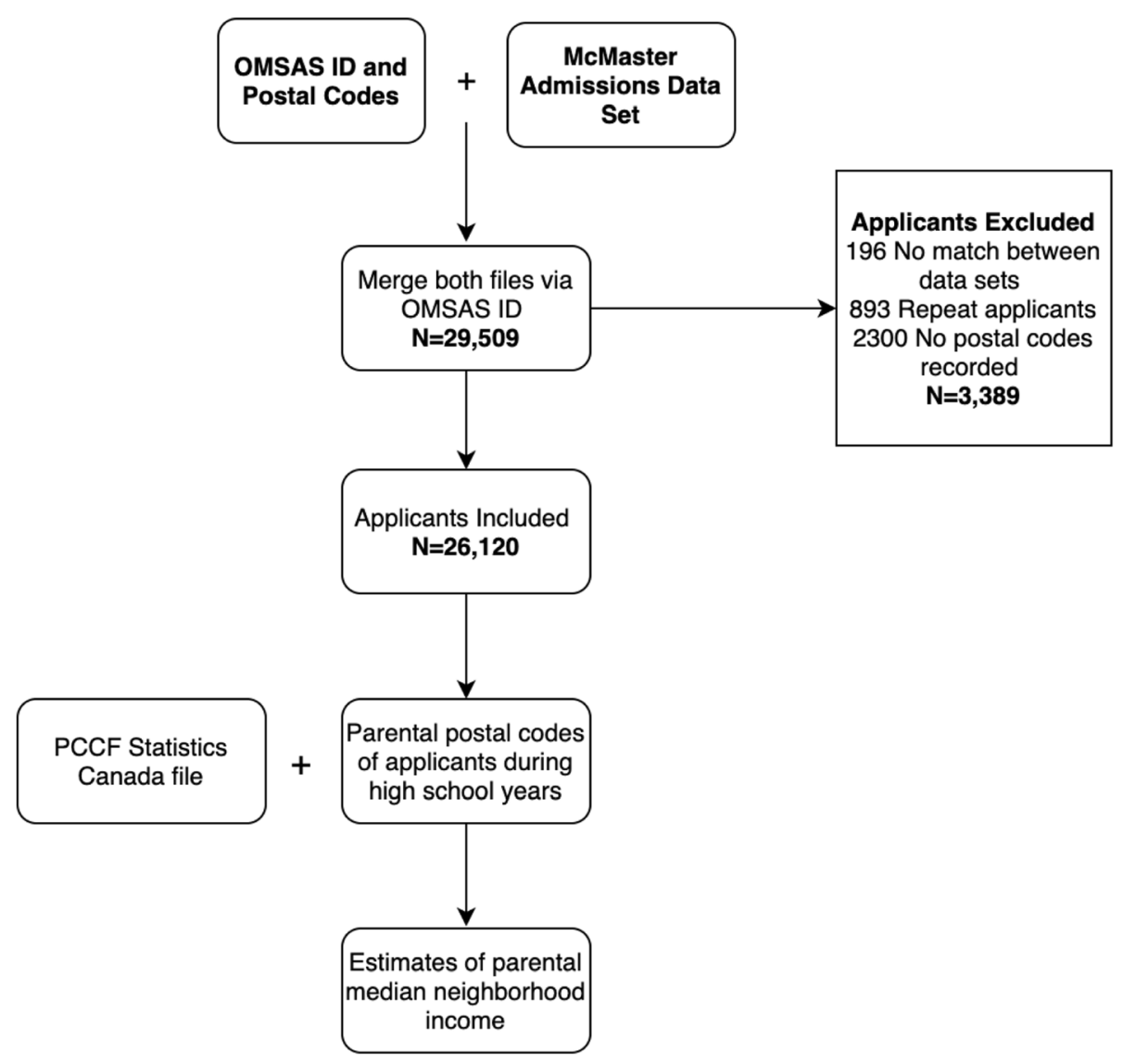

Fig. 1 Flow chart summarizing the study process of file merger, data inclusion and exclusion methods

had a statistically higher median neighborhood income of $\$ 105,984.00(p=<0.001)$. Figure 2 compares the provincial median incomes with all, and accepted applicant's median neighborhood incomes and Fig. 3 compares the median total household income distribution of Canadians, all and accepted applicants' neighborhood income. These results are in keeping with a 2012 survey study that examines the economic diversity of medical school students [11]. Table 1 summarizes the results of the descriptive statistics.

Our sensitivity analysis revealed consistent results; when excluding Ontario applicants, the total median neighborhood income was approximately $\$ 97,024.00$ for all applicants and $\$ 109,952.00$ for accepted applicants $(p=<0.001)$.

\section{Results of regression analyses}

There was a statistically significant relationship between applicants' median total neighborhood income and an offer of admission in our unadjusted model. When comparing quartiles of neighborhood income, there is an increase in odds of admission offer with each increase in neighborhood income quartile. In comparison with an applicant in the $<25$ th percentile to an applicant in the
$>75$ th percentile, there is an increase in odds of $54 \%$ for an offer of admission. The Naegelkerke's $R^{2}$ result for this model was 0.06 . Table 2 summarizes the results of this model.

The binary logistic regression models, adjusted for GPA, MMI, CASPer and MCAT scores, did not show statistically significant results with regard to neighborhood income. In the first model, there was a nonsignificant trend that showed as your income increases, your odds of being offered admission increases. In the second model, there is a contradictory trend. Importantly, the neighborhood income of the applicants in the first model was $\$ 98,816$ and the neighborhood income of the applicants of the second model is much higher at $\$ 104,960(p<0.001)$. Importantly, the models need to be interpreted with the understanding the variables in the model are completely determined by the outcome, therefore there is little discretion for other variables to have an impact. The Naegelkerke's $R^{2}$ result for these models were 0.7 and 0.8 respectively. Tables 3 and 4 summarize these results.

\section{Pearson coefficients analyses}

We performed Pearson coefficients for an offer of admission to academic scores, offer of interview and 


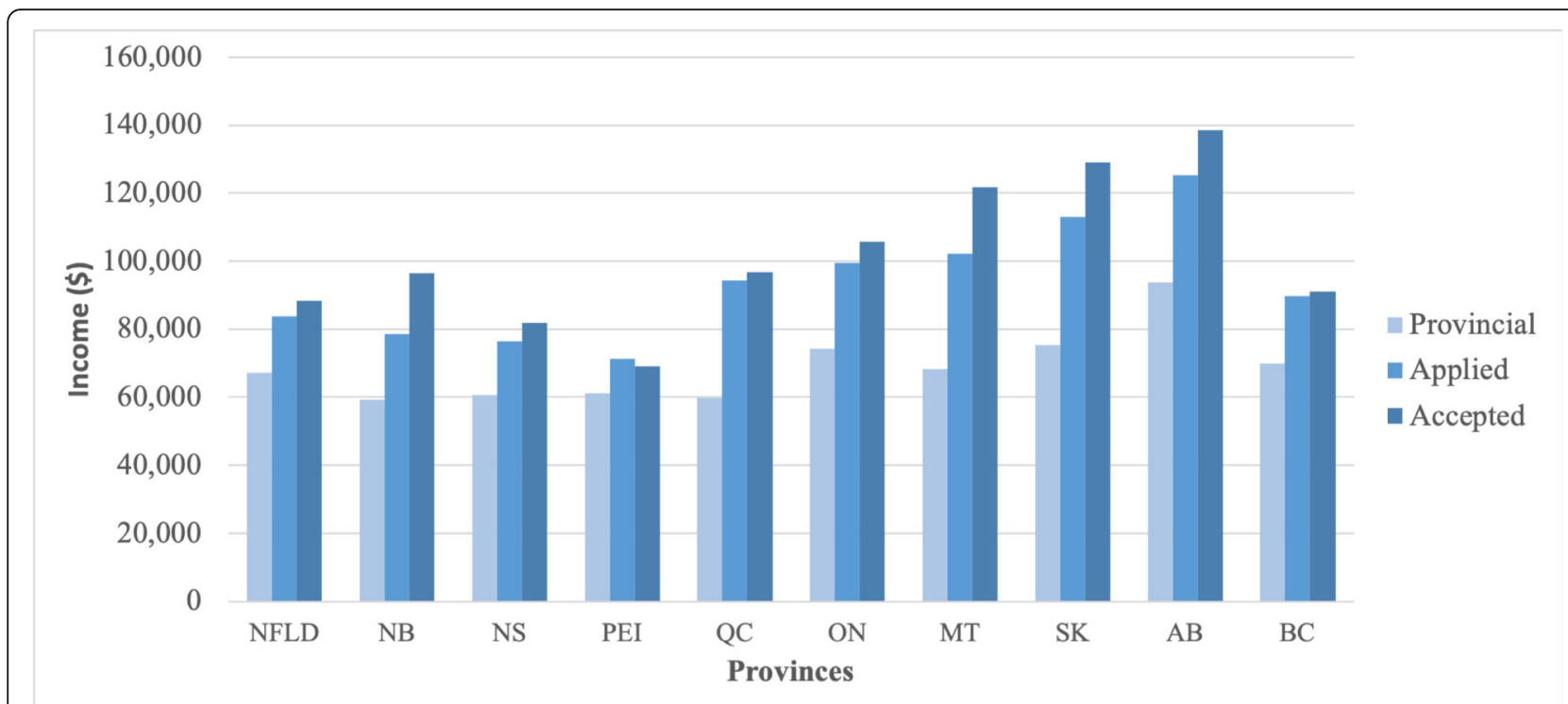

*Information from Statistics Canada Census 2016

$N F L D=$ Newfoundland \& Labrador; $N B=$ New Brunswick; NS=Nova Scotia $;$ PEI=Province Edward Island; $Q C=Q u e b e c ; O N=$ Ontario; $M T=$ Manitoba; $S K=$ Saskatchewan AB=Alberta; $B C=$ British Columbia.

Fig. 2 Income distribution of applicants by province for all and accepted applicants, compared against their respective provincial total median household incomes*. *Information from Statistics Canada Census 2016. NFLD = Newfoundland \& Labrador; NB=New Brunswick; NS=Nova Scotia; PEI= Province Edward Island; $Q C=$ Quebec; $O N=$ Ontario; $M T=$ Manitoba; SK=Saskatchewan $A B=$ Alberta; $B C=B r i t i s h$ Columbia

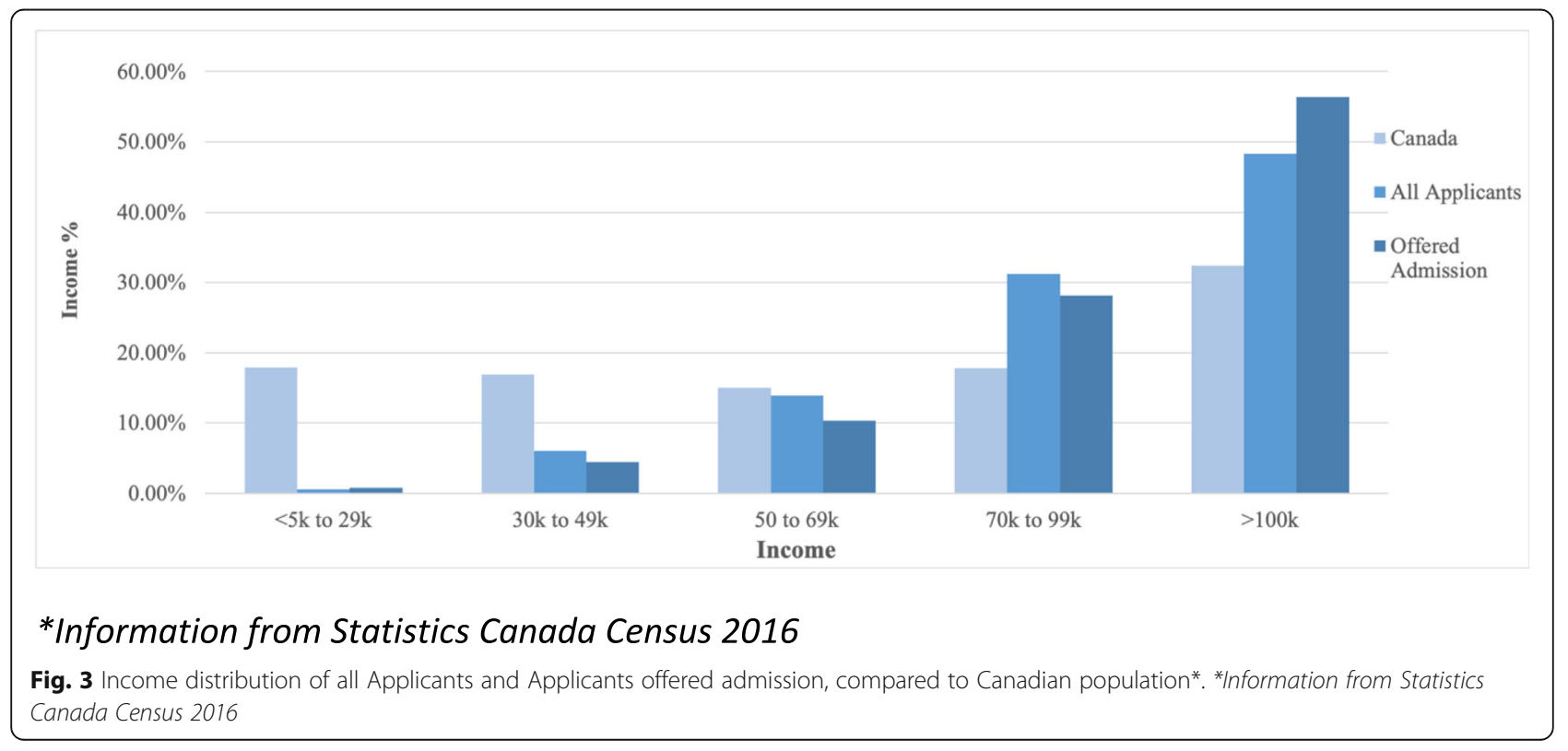


Table 1 Characteristics of medical school applicants by offer of admission, among applicants at McMaster University (2013 to 2018, $N=26,120$ )

\begin{tabular}{|c|c|c|c|c|}
\hline Characteristic & All Applied $(N=26,120 ; 100 \%)$ & Offered Admission ( $N=1777 ; 6.8 \%$ ) & Not Offered $(N=24,343 ; 93.2 \%)$ & $p$-value \\
\hline Age (Mean, SD) & $23.1, \pm 3.2$ & $22.0, \pm 2.6$ & $23.2, \pm 3.2$ & $<0.001$ \\
\hline $\operatorname{Sex}(\%, n)$ & & & & $<0.001$ \\
\hline Female & $55.1 \%, 14,397$ & $57.8 \%, 1026$ & $54.9 \%, 13,412$ & \\
\hline Male & $44.9 \%, 11,723$ & $42.2 \%, 750$ & $45.1 \%, 11,021$ & \\
\hline Geography (n, \%) & & & & $<0.001$ \\
\hline Ontario & $19,628,75.0 \%$ & $1547,87.0 \%$ & $18,081,74.3 \%$ & \\
\hline Quebec & $591,2.3 \%$ & $11,0.6 \%$ & $580,2.4 \%$ & \\
\hline Atlantic & $1016,3.9 \%$ & $36,2.0 \%$ & $980,4.0 \%$ & \\
\hline Prairies & $2240,8.6 \%$ & $86,4.8 \%$ & $2154,8.9 \%$ & \\
\hline British Columbia & $2614,10.0 \%$ & $97,5.4 \%$ & $2517,10.3 \%$ & \\
\hline Territories & $31,0.1 \%$ & $0,0 \%$ & $31,0.1 \%$ & \\
\hline \multicolumn{5}{|l|}{ Income } \\
\hline Median Income \$ (n, IQR) & $98,816(123,392-74,752)$ & $105,984.00(130,816-81,770.50)$ & $98,304.00(123,392-74,752)$ & $<0.001$ \\
\hline$\leq 69 k(\%, n)$ & $20.5 \%, 5365$ & $15.5 \%, 275$ & $20.0 \%, 4887$ & \\
\hline 70 k-99 k (\%, n) & $31.2 \%, 8136$ & $28.1 \%, 500$ & $31.2 \%, 7623$ & \\
\hline$\geq 100 \mathrm{k}(\%, \mathrm{n})$ & $48.3 \%, 12,619$ & $56.4 \%, 1002$ & $48.8 \%, 11,923$ & \\
\hline Income Excluding Ontario $\$(n, I Q R)$ & $97,024.00(123,520-73,131)$ & $109,952,(132,608-78,496)$ & $96,576,(123,136-72,533)$ & $<0.001$ \\
\hline \multicolumn{5}{|l|}{ MCAT (Mean, SD) } \\
\hline Verbal Reasoning & $9.4, \pm 1.8$ & $11.1, \pm 1.1$ & $9.2, \pm 1.7$ & $<0.001$ \\
\hline CARS & $126.2, \pm 2.3$ & $129.2, \pm 1.5$ & $126.0, \pm 2.3$ & $<0.001$ \\
\hline Grade Point Average (Mean, SD) & $3.6, \pm 0.4$ & $3.9, \pm 0.1$ & 3.6, \pm 0.4 & $<0.001$ \\
\hline CASPer (Mean, SD) & $4.6, \pm 1.2$ & $5.7, \pm 0.9$ & $4.5, \pm 1.2$ & $<0.001$ \\
\hline MMI (Mean, SD) ${ }^{a}$ & $6.4, \pm 1.1$ & $7.0, \pm 0.7$ & $5.4, \pm 0.8$ & 0.10 \\
\hline
\end{tabular}

Abbreviations: $S D=$ Standard Deviation, $I Q R=$ Interquartile Range, Household income $=2015$ total income of households for most appropriate dissemination area.; $M C A T=$ Medical college admissions test. CARS=Critical Analysis and Reasoning section. MMI = Multi-Mini Interview, Household income $=2015$ total income of households for most appropriate dissemination area

${ }^{a}$ Only 2973 have an MMI score, as they represent the cohort of applicants offered an interview after the pre-test score

Table $2{ }^{a}$ Adjusted associations between demographic characteristics and Offer of Admission, among Medical School Applicants (2013 to 2018, N=26,120)

\begin{tabular}{|c|c|c|c|}
\hline Variable & Odds Ratio (Adjusted) & $p$-value & $95 \% \mathrm{Cl}$ \\
\hline \multicolumn{4}{|c|}{ Neighborhood Income } \\
\hline$<25$ th percentile & 1 & $<0.001$ & \\
\hline $\begin{array}{l}\text { 25th to } 49 \text { th } \\
\text { percentile }\end{array}$ & 1.2 & 0.005 & 1.06 to 1.44 \\
\hline $\begin{array}{l}\text { 50th to } 75 \text { th } \\
\text { percentile }\end{array}$ & 1.4 & $<0.001$ & 1.21 to 1.62 \\
\hline$>75$ th percentile & 1.5 & $<0.001$ & 1.34 to 1.78 \\
\hline \multicolumn{4}{|l|}{ Age } \\
\hline $\begin{array}{l}\text { Per increase in } \\
1 \text { year }\end{array}$ & 0.8 & 0.019 & 0.83 to 0.87 \\
\hline \multicolumn{4}{|l|}{ Sex } \\
\hline Female & 1 & & \\
\hline Male & 0.9 & 0.02 & 0.81 to 0.98 \\
\hline \multicolumn{4}{|l|}{ Residence statu ${ }^{b}$} \\
\hline Out of province & 1 & & \\
\hline Ontario & 3.0 & $<0.001$ & 2.56 to 3.63 \\
\hline
\end{tabular}

neighborhood income, which showed that an offer of interview correlated the strongest with overall chance of being offered admission, with a positive Pearson coefficient of 0.75 . No significant collinearity was found between these variables. Table 5 summarizes the results of the Pearson coefficients.

\section{Discussion}

Our study confirmed that applicants from areas with higher total neighborhood incomes were more likely to apply and to be offered admission to medical school. We found that the median neighborhood income of all applicants was $33.7 \%$ percent higher than the Canadian median total household income. Applicants that were offered admission had a $40.4 \%$ higher neighborhood income than the national median [13]. Furthermore, 48.3\% of all applicants had a median total neighborhood income bracket greater than or equal to $\$ 100,000$. We demonstrated that applicants from greater than or equal to $\$ 100,000$ form most successful applicants, with $56.4 \%$ coming from areas with median neighborhood incomes greater than or equal to $\$ 100,000$. In addition, we 
Table $3^{\text {a }}$ Second model: GPA, MCAT, and CASPer (Preinterview score)

\begin{tabular}{|c|c|c|c|}
\hline Variable & $\begin{array}{l}\text { Odds Ratio } \\
\text { (Adjusted) }\end{array}$ & $p$-value & $95 \% \mathrm{Cl}$ \\
\hline \multicolumn{4}{|l|}{ Income } \\
\hline$<25$ th percentile & 1 & 0.866 & \\
\hline 25th to 49th percentile & 1.1 & 0.692 & 0.76 to 1.51 \\
\hline 50th to 75 th percentile & 1.0 & 0.810 & 0.75 to 1.46 \\
\hline$>$ 75th percentile & 1.1 & 0.426 & 0.82 to 1.60 \\
\hline \multicolumn{4}{|l|}{ Admission Tests } \\
\hline MCAT & 2.9 & $<0.001$ & 2.68 to 3.15 \\
\hline GPA & 2.3 & $<0.001$ & 2.0 to 2.4 \\
\hline CASPer & 9.8 & $<0.001$ & 8.1 to 11.8 \\
\hline \multicolumn{4}{|l|}{ Age } \\
\hline Per increase in 1 year & 1.0 & 0.432 & 0.97 to 1.1 \\
\hline \multicolumn{4}{|l|}{ Sex } \\
\hline Male & 1 & $<0.001$ & \\
\hline Female & 1.5 & $<0.001$ & 1.23 to 1.94 \\
\hline \multicolumn{4}{|l|}{ Residency status $^{b}$} \\
\hline Out of Province & 1 & 0.998 & \\
\hline Ontario & 4.3 & 0.275 & 0.31 to 58.3 \\
\hline
\end{tabular}

This represents the first part of McMaster's formula for selection of applicants, representing 26,120 applicants

${ }^{\mathrm{b}}$ Residence status is used by McMaster university to help determine an offer of interview

Table $4^{\text {a }}$ Third model: GPA, MCAT, and MMI (Post-interview score)

\begin{tabular}{|c|c|c|c|}
\hline Variable & $\begin{array}{l}\text { Odds Ratio } \\
\text { (Adjusted) }\end{array}$ & $p$-value & $95 \% \mathrm{Cl}$ \\
\hline \multicolumn{4}{|l|}{ Income } \\
\hline$<25$ th percentile & 1 & 0.885 & \\
\hline 25th to 49th percentile & 0.8 & 0.434 & 0.42 to 1.45 \\
\hline 50th to 75 th percentile & 0.9 & 0.700 & 0.48 to 1.63 \\
\hline$>$ 75th percentile & 0.8 & 0.579 & 0.46 to 1.55 \\
\hline \multicolumn{4}{|l|}{ Admission Tests } \\
\hline MCAT & 1.7 & $<0.001$ & 1.43 to 1.92 \\
\hline GPA & 1.5 & 0.001 & 1.20 to 1.70 \\
\hline $\mathrm{MMl}$ & 51.2 & $<0.001$ & 31.9 to 82.0 \\
\hline \multicolumn{4}{|l|}{ Age } \\
\hline Per increase in 1 year & 1.00 & 0.998 & 0.89 to 1.1 \\
\hline \multicolumn{4}{|l|}{ Sex } \\
\hline Male & 1 & 0.555 & \\
\hline Female & 1.1 & 0.766 & 0.71 to 1.58 \\
\hline \multicolumn{4}{|l|}{ Residency status $^{b}$} \\
\hline Out of Province & 1 & 0.784 & \\
\hline Ontario & 1.5 & 0.248 & 0.74 to 3.27 \\
\hline
\end{tabular}

${ }^{a}$ This represents the second part of McMaster's formula for selection of applicants, with 2973 applicants included

${ }^{\mathrm{b}}$ Residence status is used by our university to determine offer of interview
Table 5 Bivariate Pearson coefficient on academic scores, offer of interview and neighborhood income

\begin{tabular}{lll}
\hline Variable & Pearson Coefficient & $P$-value \\
\hline Admission & 1 & \\
Interview Invite & 0.75 & $<0.001$ \\
MCAT & 0.34 & $<0.001$ \\
CASPer & 0.26 & $<0.001$ \\
GPA & 0.18 & $<0.001$ \\
Income & 0.05 & $<0.001$ \\
\hline
\end{tabular}

showed that our analysis is not biased by our large Ontario cohort.

\section{Regression models}

Although neighborhood income in our adjusted binary regression model was not significant when correcting for MCAT, CASPer, MMI and GPA, this is to be expected, as McMaster's pre-interview score is generated as a function 33\% for each component and therefore leaves no discretion. Similarly, the MMI is weighted at $70 \%$ post-interview score, with MCAT and GPA accounting for $15 \%$ each. Interestingly, our first and second model, summarized in Tables 3 and 4, show contradictory results. We believe this to be an important finding. The first model represents the phase of the application process where academic scores such as MCAT, GPA and CASPer completely determine an offer of interview. This group of applicants had a median neighborhood income of $\$ 98,816$. Interestingly, in the second model, which is a smaller cohort of successful applicants from the first model, had a significantly higher income of $\$ 104,960$, which is approximately the income of applicants offered admission. This suggest that the applicants of lower socioeconomic background are disadvantaged in the first round of the application process. This is in keeping with an established literature that success in these exams correlates with income $[14,15]$. In the second round, the interpretation is less clear. Either income is less of a factor, perhaps from the MMI having so much weight ( $70 \%$ of the total score) or because the applicant cohort is now of significantly higher incomes, and therefore there is no variability for the model to test. Although it has been previously established that medical school applicants tend to be from higher income households [2,11], our study is significant because, despite institutional calls to action and knowledge of these facts for decades, we show that there is still significant disparity in the socioeconomic diversity of medical school admissions. It also points to a particular aspect of the application process, namely the pre-interview process, that may be disadvantageous to lower socioeconomic applicants. 


\section{Applicant advantage in an already biased cohort}

We found that applicants from areas with a greater median neighborhood income tend to be accepted into medical school. Measures used to rank students, such as the MCAT, can have significant financial barriers, with a large financial market for preparation courses. This is in keeping with literature suggesting that MCAT, other admissions tests and application fees correlate significantly with applicant's income [14-18]. This is also consistent with our discussion above, namely that the part of the application process that is determined by these scores may be influenced by socioeconomic status. Importantly, neighborhood income remains a predictor of success despite the significant skew in all applicants who already are disproportionately from neighborhood incomes of above $\$ 100,000$ and is demonstrated visually in Fig. 2.

\section{Applicants from higher SES are more likely to apply}

To our knowledge, we are the first to demonstrate that applicants from areas with a greater median neighborhood income are more likely to apply to medical school in the first place. These results remain significant even when dispensing with our large Ontario cohort. These findings suggest that there are critical advantages in higher income areas that result in an overrepresentation in medical school applicants. Some advantages may directly relate to the measures used in an offer of admission, as they are often associated with expensive preparatory courses that can deter many lowincome applicants from applying. Application fees are expensive and have been identified as a potential limiting factor for persons of lower socioeconomic status [19]. Taken together, these factors can aggregate and can form a perception that many potential applicants have regarding their chances of being offered admission. For example, rural students in Newfoundland reported feeling they would have a harder time being accepted to medical school and that medicine was not promoted as a potential career [16]. In addition, high school applicants in Southwestern Ontario reported feeling that finances were a potential barrier to being accepted into medical school. Interestingly, these feelings correlated with parental neighborhood income and circumstance [20]. These examples exemplify self-selection, which are the preconceived notions that act to limit potential applicants from applying in the first place.

\section{Offer of interview, admission and income}

Interestingly, our Pearson coefficient analysis reveals an important correlate with an offer of admission, namely that an offer of an interview correlates strongest with an offer of admission. We found that on an individual basis, an offer of interview correlated more with an offer of admission than any of the academic score or neighborhood income. Interestingly, based on our models in Tables 3 and 4, this also represents a significant change in the neighborhood income distribution of applicants. Therefore, indirectly representing a bias for applicants of lower socioeconomic status. From our knowledge, we are the first report this particular finding.

\section{Impact}

Our study contributes to the broader debate on the importance of medical school diversity and quantifies the magnitude of the current problem. Specifically, we are the first to report on the direct relationship that neighborhood income has in medical admissions as well as characterizing applicants to medical school. First, at our institution, this study provides an in-depth analysis of the current status of our socioeconomic diversity and will direct focus on further study to inform policy changes. Second, this study may galvanize medical programs across Ontario and Canada to characterize their respective economic diversity profiles and continue to address this issue. Importantly, it should galvanize a discussion around the concept of hidden biases. There is no direct measure of socioeconomic status in medical admissions, but the assessments used in determining success in medical admissions have positive correlations with ascending affluence. Although this study is at one institution, our data set includes approximately $74.6 \%$ of all Ontario medical school applicants and $21.4 \%$ of all admitted registrants to an Ontario medical school [7].

\section{Limitations}

Our study has many strengths but several notable limitations. Although our data set is large, our study includes only a single institution and therefore our findings may not generalize to all medical schools in Canada. However, our study includes relatively large contributions from every province and territory and is larger than any other study on the subject to date. Furthermore, McMaster is recognized as a leader in inclusive medical admissions. They are the developers of the MMI and CASPer, as well as research on equity in medical school [21-25]. In addition, our socioeconomic proxy measure of median neighborhood income is based on postal codes and may not be reflective of the income of all medical applicant households. Furthermore, the neighborhood income of rural households is difficult to estimate in this manner [26]. However, we suspect that this would only make our findings more conservative. Finally, although our report identifies important associations, we cannot determine with certainty the causative mechanism(s) behind our findings, although we have postulated reasonable theories. 


\section{Conclusion}

Our analysis demonstrated that the general pool of medical school applicants is skewed towards the upper quartiles of neighborhood income and are not representative of the national income distribution. Furthermore, neighborhood income is associated with success in the medical school admissions process, although with uncertain etiology. This is despite a recent institutional call to action to improve the socioeconomic diversity of medical school admissions. Future studies should focus on investigating the mechanism of the association to inform efforts to mitigate the bias, in order to fulfill the obligation, set out by the AFMC to encourage a more socioeconomically diverse physician workforce.

\section{Supplementary information}

Supplementary information accompanies this paper at https://doi.org/10. 1186/s12909-020-02126-0.

Additional file 1: Table 1. Subgroups of applicants in Tables 3 and 4

\section{Abbreviations}

AFMC: Association of faculties of medicine of Canada; MCAT: Medical college admissions test; OMSAS: Ontario medical school application service: VR: Verbal reasoning; MMI: Multi-mini interview; GPA: Grade point average; CASPER: Computer-based assessment for sampling personal characteristics; PCCF: Postal code conversion file; DA: Dissemination Area; SPSS: Statistical Package for the Social Sciences

\section{Acknowledgements}

We would like to thank the WRC McMaster research team for their support in this project.

\begin{abstract}
Authors' contributions
All authors have read and approved the manuscript. TP is a first year Internal Medicine Resident McMaster University. He came up with the project idea, helped design the research project, acquire the data and write and copywrite the manuscript. AT is a Family Medicine Resident at Queen's University. He helped design the research project, acquire the data and write and copyedit the final manuscript. KE is a Family Medicine Resident at McMaster University. He performed an extensive literature review, helped write and copy-edit the final manuscript. AJ is a PhD candidate in the Department of Health Research Methods, Evidence, and Impact, McMaster University. He helped design the statistical methods and write and copy-edit the final manuscript. MM is the Regional Assistant Dean of the Michael G. DeGroote School of Medicine Waterloo Regional Campus. She helped acquire the data, design the project and write the final manuscript. AC is the Schlegel Research Chair in Clinical Epidemiology and Aging; Assistant Professor in the Department of Health Research Methods, Evidence, and Impact and the Department of Medicine; and Research Director at the Michael G. DeGroote School of Medicine Waterloo Regional Campus, McMaster University. AC was the research supervisor, helped acquire the data, and write and copy-edit the final manuscript.
\end{abstract}

\section{Funding}

None.

\section{Availability of data and materials}

Due to the sensitivity of the data in the study, we cannot make all data available but individual requests can be made and will be given individual assessment. Requests should be made to the corresponding author.

\section{Ethics approval and consent to participate}

Given the use of secondary de-identified data, strict information security, and institutional sponsorship/oversight, this project was granted a waiver of full review by the Hamilton Integrated Research Ethics Board on the basis of low risk / quality improvement. Administrative review and release were granted by the admissions committee and assistant dean of medicine.

\section{Consent for publication}

Not applicable.

\section{Competing interests}

None.

Received: 11 January 2020 Accepted: 24 June 2020

Published online: 01 July 2020

\section{References}

1. Khan $\mathrm{R}$, et al. Socioeconomic Status as a Determinant for Medical School Admissions. Retrieved from https://omsa.ca/en/positionpapers/ socioeconomic-status-determinant-medical-school-admissions.

2. Dhalla IA, Kwong JC, Streiner DL, Baddour RE, Waddell AE, Johnson IL. Characteristics of first-year students in Canadian medical schools. CMAJ. 2002;166(8):029-1035.

3. Kwong JC, Dhalla IA, Streiner DL, Baddour RE, Waddell AE, Johnson IL. Effects of rising tuition fees on medical school class composition and financial outlook. CMAJ. 2002;166(0820-3946 (Print)):1023-1028.

4. The Future of Medical Education in Canada (FMEC): A Collective Vision for MD Education.

5. Nickens $\mathrm{H}$, Smedley B. The right thing to do, the smart thing to do: increasing racial and ethnic diversity among physicians: an intervention to address health disparities? Washington, D.C.: National Academy Press; 2001.

6. Horvat L, Horey D, Romios P, Kis-Rigo J. Cultural competence education for health professionals. Cochrane Database Syst Rev. 2014. https://doi.org/10. 1002/14651858.cd009405.pub2

7. "Medical School Application Statistics | Ontario Universities' Application Centre.". ontario medical students association. https:/omsa.ca/sites/default/ files/policy_or_position_paper/41/position_paper_socioeconomic_status_ as_a_determinant_of_medical_school_admissions_2016_mar.pdf.

8. Shipper E, Mazer L, Merrell S, Lin D, Lau J, Melcher M. Pilot evaluation of the computer-based assessment for sampling personal characteristics test. J Surg Res. 2017;215:211-8. https://doi.org/10.1016/j.jss.2017.03.054.

9. Dore K, Reiter H, Kreuger S, Norman G. CASPer, an online pre-interview screen for personal/professional characteristics: prediction of national licensure scores. Adv Health Sci Educ. 2016;22(2):327-36. https://doi.org/10. 1007/s10459-016-9739-9.

10. Wilkins R. Use of postal codes and addresses in the analysis of health data. Health Rep. 1993;5(2):157-77 https://www.ncbi.nlm.nih.gov/pubmed/8292756.

11. Southern D, Faris P, Knudtson M, Ghali W. Prognostic relevance of censusderived individual respondent incomes versus household incomes. Can J Public Health. 2006;97(2):114-7. https://doi.org/10.1007/bf03405327.

12. Honein-AbouHaidar G, Baxter N, Moineddin R, Urbach D, Rabeneck L, Bierman A. Trends and inequities in colorectal cancer screening participation in Ontario, Canada, 2005-2011. Cancer Epidemiol. 2013;37(6): 946-56. https://doi.org/10.1016/j.canep.2013.04.007.

13. Canada S. Census of Population, 2016 Guide to the Census of Population Census of Population Reference Product [Internet]. 2016 [cited 2019 Jul 7].

14. Reiter HI, Lockyer J, Ziola B, Courneya CA, Eva K. Should efforts in favor of medical student diversity be focused during admissions or farther upstream? Acad Med. 2012;87(4):443-8. https://doi.org/10.1097/ACM. ob013e318248f7f3.

15. Grbic D, Jones DJ, Case ST. The role of socioeconomic status in medical school admissions: validation of a socioeconomic Indicator for use in medical school admissions. Acad Med. 2015;90(7):953-60. https://doi.org/10. 1097/ACM.0000000000000653.

16. Whalen D, Harris C, Harty C, et al. Should I apply to medical school? High school students and barriers to application. Can J Rural Med. 2016;21(2):4650 http://www.ncbi.nlm.nih.gov/pubmed/26986684. Accessed September 15, 2019.

17. Jerant A, Fancher T, Fenton JJ, et al. How medical school applicant race, ethnicity, and socioeconomic status relate to multiple mini-interview-based admissions outcomes: findings from one medical school. Acad Med. 2015: 90(12):1667-74. https://doi.org/10.1097/ACM.0000000000000766.

18. Fortin Y, Kulasegaram K (Mahan), Kancir JN, Moineau G, Carpentier A, Hanson MD. The direct economic and opportunity costs of the Medical 
College Admissions Test (MCAT) for Canadian medical students. MedEdPublish. 2018;7(4). doi:https://doi.org/10.15694/mep.2018.0000243.1.

19. Ghaffari RA. Secondary medical school applications place an unfair financial burden on middle- and lower-income applicants. Acad Med. 2017;92(6):728. https://doi.org/10.1097/ACM.0000000000001694.

20. Cassidy K, Foster T, Moody E, Turner J, Tejpar S. Perceptions of medica school among high school students in southwestern Ontario. Can J Rural Med. 2013;18(1):7-12 http://www.ncbi.nlm.nih.gov/pubmed/23259962. .

21. Eva KW, Rosenfeld J, Reiter HI, Norman GR. An admissions OSCE: the multiple mini-interview. Med Educ. 2004;38(3):314-26. https://doi.org/10. 1046/.j.1365-2923.2004.01776.x.

22. Reiter HI, Eva KW, Rosenfeld J, Norman GR. Multiple mini-interviews predict clerkship and licensing examination performance. Med Educ. 2007;41(4): 378-84. https://doi.org/10.1111/j.1365-2929.2007.02709.x.

23. Eva KW, Reiter HI, Rosenfeld J, Trinh K, Wood TJ, Norman GR. Association between a medical school admission process using the multiple miniinterview and National Licensing Examination Scores. Jama. 2012;308(21): 2233. https://doi.org/10.1001/jama.2012.36914

24. Reiter HI, Eva KW. APPLIED RESEARCH: Reflecting the relative values of community, faculty, and students in the admissions tools of medical school. Teach Learn Med 2005;17(1):4-8. doi:https://doi.org/10.1207/ s15328015tlm1701_2.

25. Reiter HI, Lockyer J, Ziola B, Courneya C-A, Eva K. Should efforts in favor of medical student diversity be focused during admissions or farther upstream? Acad Med. 2012;87(4):443-8. https://doi.org/10.1097/acm Ob013e318248f7f3.

26. Statistics Canada. Geography division. Postal Code Conversion File (PCCF), Reference Guide. Statistics Canada; 2003.

\section{Publisher's Note}

Springer Nature remains neutral with regard to jurisdictional claims in published maps and institutional affiliations.

Ready to submit your research? Choose BMC and benefit from:

- fast, convenient online submission

- thorough peer review by experienced researchers in your field

- rapid publication on acceptance

- support for research data, including large and complex data types

- gold Open Access which fosters wider collaboration and increased citations

- maximum visibility for your research: over $100 \mathrm{M}$ website views per year

At $\mathrm{BMC}$, research is always in progress.

Learn more biomedcentral.com/submissions 